Egyptian J. of Nutrition Vol. XXXV No. 2 (2020)

\title{
A 12- week egg-based dietary intervention promotes lipid and lipoproteins profiles in older adults
}

\author{
Shymaa M. Ata. \\ Department of Home Economics, Faculty of Specific Education, \\ Menoufia University, Menoufia, Egypt
}

\begin{abstract}
Eggs are a good and an inexpensive source of important nutrients including high-quality protein, vitamins, and lutein and zeaxanthin. However, consumption of eggs is restricted due to its cholesterol content. The aim of the study was to evaluate whether consumption of one regular or lutein-fortified egg per day as part of a regular diet for 3-month would favorably affect lipid and lipoproteins profiles in apparently healthy, older adults 40-79 y. The study utilized a randomized, single-blind, placebo-controlled, parallel groups design in which subjects ( $n=33 ; 8$ males, 25 females) were randomly assigned to one of the following three groups: 1) egg substitute (SUB, $\mathrm{n}=12$; one egg substitute providing $0 \mu \mathrm{g}$ lutein and $0 \mathrm{mg}$ cholesterol); 2) egg (EGG, $n=10$; one whole egg providing $200 \mu \mathrm{g}$ of lutein and $230 \mathrm{mg}$ of cholesterol); 3) lutein-fortified egg (EGG-L, $\mathrm{n}=11$; one fortified egg providing $260 \mu \mathrm{g}$ of lutein and $230 \mathrm{mg}$ of cholesterol). Following egg consumption, HDL average particle size increased $(P=0.03)$, total VLDL $(P=0.003)$ and small VLDL $(P=$ $0.008)$ particle numbers decreased, while total LDL particle numbers tend to be decreased $(P=0.07)$. Changes in HDL average particle size associated positively with changes in serum HDL-C
\end{abstract}


Shymaa M. Ata.

concentration $(r=0.55, P=0.003)$. Changes in apB concentration were inversely related to changes in total LDL particle numbers (rho $=0.47, P=0.006$ ). This study supports that moderate egg consumption actually promotes favorable lipid and lipoprotein subfraction profiles.

\section{Introduction}

Cardiovascular diseases (CVD) are increasing in prevalence and one of the major causes of death in western countries (Watkins, 2004). Atherosclerosis is a main contributor to CVD and is characterized by the hardening and thickening of the artery wall caused by accumulation of lipid-filled plaques in the arteries. High blood cholesterol concentration or hypercholesterolemia is one of the well-established factors for atherosclerosis. Cholesterol-lowering therapies are at the forefront of CVD management strategies (Ross, 1999 and Ivanova, 2017).

Lipoprotein particles are consisting of an insoluble lipid core, primarily triacylglycerol and cholesteryl ester. The hydrophobic core is surrounded by a hydrophilic membrane consisting of phospholipid, free cholesterol, and proteins called apolipoproteins. Plasma lipoproteins are classified based on size, lipid composition, and apolipoproteins to seven classes (chylomicrons, chylomicron remnants, very low-density lipoproteins (VLDL), intermediate -density lipoproteins (IDL), low-density lipoproteins (LDL), high-density lipoproteins (HDL), and lipoprotein (a)). Lipoproteins are important for lipid transport in the circulation (Walldius \& Jungner, 2004; Feingold \& Grunfrld, 2018). 
Egyptian J. of Nutrition Vol. XXXV No. 2 (2020)

Lipoprotein particle size is related to particle atherogenicity. For example, small LDL particles are more susceptible to oxidation. Oxidized LDL (oxLDL) is the principle cause of plaque formation, which results in atherosclerosis and CVD (Carmena et al., 2004). By contrast, larger more buoyant HDL is associated with decreased CVD risk (Kosmas et al., 2018).

Apolipoproteins play an important role in lipoprotein formation, uptake, and metabolism (Mahley et al, 1984). Apolipoprotein B (apoB) 100 is synthesized in the liver and is present in LDL, IDL, and VLDL particles. Each lipoprotein particle contains one apo $B$ molecule therefore the total apo $B$ value indicates the total number of potentially atherogenic lipoproteins (Walldius \& Jungner, 2004; Kaneva et al., 2015). An excess of apo-B containing particles is associated with increased cardiovascular risk (Lamarche et al., 1996; Walldius et al., 2001; Williams et al., 2003; Corsetti et al., 2004; St-Pierre, 2006).

Apolipoprotein A-I (apoA-1) is the main structural protein in high density lipoproteins (HDL) which is responsible for initiating reverse cholesterol transport (RCT) process, whereby excess cholesterol from peripheral tissues is carried back to the liver for secretion into bile, and hence decreases the risk for atherosclerosis (Oram et al., 2005; Davidson, 2009; Ouimet et al., 2019). Each HDL particle may contain several ApoA-I molecules. An increase in apoA-I concentrations may be associated with increased RCT (Negre-Salvayre et al., 2006).

Eggs are a good and an inexpensive source of important nutrients including protein, vitamins, and lutein and zeaxanthin. However, eggs have largely been left from heart healthy diets 
Shymaa M. Ata.

because of the common misconception that eggs increase serum cholesterol and hence atherosclerotic risk. The goal of the present study was to determine the effects of consuming one egg per day for 12-wk on lipid and lipoprotein subfractions profile in healthy, older adults.

\section{Materials and Methods}

\section{Subjects:}

A convenience sample of healthy adult men and women (4079 y) were recruited from the University of Connecticut and the surrounding community. All adults underwent a screening examination and were asked to fill out a personal data and medical history questionnaire. Subjects were excluded from the study if they met one or more of the exclusion criteria. Thirty-three participants provided informed and written consent and were compensated for their participation. The study protocol was approved by the University of Connecticut-Storrs Institutional Review Board.

\section{Study design:}

The study utilized a randomized, single-blind, placebocontrolled, parallel groups design in which subjects were randomly assigned to one of the following three groups: 1) egg substitute (SUB, $\mathrm{n}=12$; one egg substitute providing $0 \mu \mathrm{g}$ lutein and $0 \mathrm{mg}$ cholesterol); 2) egg (EGG, $n=10$; one whole egg providing $200 \mu \mathrm{g}$ of lutein and $230 \mathrm{mg}$ of cholesterol); 3) lutein-fortified egg (EGG-L, $\mathrm{n}=11$; one fortified egg providing $260 \mu \mathrm{g}$ of lutein and $230 \mathrm{mg}$ of cholesterol). Lutein powder $(600 \mu \mathrm{g})$ was added and mixed with liquid regular eggs to reach a final concentration of $260 \mu \mathrm{g}$ per egg. Subjects were asked to consume one egg per day with no more than seven eggs per week and were asked not to skip more than two 
Egyptian J. of Nutrition Vol. XXXV No. 2 (2020)

consecutive days without eating eggs. Subjects also were instructed to refrain from consuming eggs other than those provided by the study and to maintain their habitual diet and level of exercise throughout the 12-wk intervention.

\section{Blood samples:}

Blood samples from venipuncture were collected between 7 and 9 am after 12-h fasting on two different days in the same week at each time point. One blood draw $(7 \mathrm{ml})$ was used to measure plasma lipids only while the second blood draw $(60 \mathrm{ml})$ was aliquoted and stored at $-80^{\circ} \mathrm{C}$ until analyzed for other variables (e.g. lipoproteins subpopulations size and number).

\section{Dietary assessments:}

The diet of each subject was monitored with a food frequency questionnaire, Fred Hutchinson Cancer Research Center food frequency questionnaire-gsel version, completed at baseline and two 5-day food records completed at wk 6 and wk 12 to check the compliance with egg or egg substitute consumption. The diet intakes records also were used to detect changes in dietary intakes that could confound the results. FFQ, a self-administrated questionnaire, was used to assess dietary intake for the study subjects over the previous month prior to the start of the study. Dietary intakes were analyzed using the Nutritional Data System for Research (NDSR) 2008 version (Minneapolis, MN).

\section{Materials:}

Liquid whole eggs and cholesterol/fat-free eggs were purchased from Vistar Corporation (Windsor, CT). Kits for total cholesterol and triglycerides were from Roche Diagnostics (Indianapolis, IN). EDTA, aprotinin, copper sulfate, sodium azid, 
Shymaa M. Ata.

phenylmethlysulfonyl fluoride (PMSF) were obtained from Sigma Chemical (St. Louis, MO). Lutein was obtained from Kemin Industries Inc. Des Moines, IA. Kits for apolipoproteins were from LINCO Research (St. Charles, Mo).

\section{Plasma lipids:}

Plasma lipids were determined using the mean of two fasting blood draws, collected on two separate days in the same week corresponding to each time point at baseline, wk 6, and wk 12 . Plasma total cholesterol was measured by enzymatic analysis using Roche Diagnostic kit (Allain et al., 1974). HDL-cholesterol was determined by measuring cholesterol in the supernatant following precipitation of the apo B containing lipoproteins (Warnick et al., 1982). LDL-C was estimated by the Freidwald equation (Freidwald et al., 1972). Plasma triglycerides were measured using Roche Diagnostic kit, which adjust for free cholesterol (Carr et al., 1993).

\section{Apolipoproteins and lipoprotein size and number:}

Plasma apolipoproteins were measured utilizing a human apolipoproteins multiplex assay kit (EMD Millipore Crop, Billerica, MA) and a Luminex 200 System (Luminex Crop, Austin, TX) at baseline and wk12. By this method, it is feasible to quantify apolipoproteins A-1, A-II, B, C-II, C-III, and E simultaneously. The technique uses fluorescently labeled microsphere beads with antibodies to each individual apolipoproteins (Liu et al., 2005).

Lipoprotein subclasses size and concentrations were measured at baseline and wk 12 by proton nuclear magnetic resonance (NMR) spectroscopy which quantifies the number of VLDL, LDL, and HDL as number of particle per liter and the size of these particles as an average particle size (nanometers). The 
Egyptian J. of Nutrition Vol. XXXV No. 2 (2020)

analysis was performed on a 400-HMz NMR analyzer
(BrukerBioSpin Crop, Billerica, MA). Different lipoproteins particles
produce different signals based on the protons in the methyl groups
in the lipids in these particles. The number of lipoproteins of a
particular size can be determined based on the amplitude of the
signals produced by a group of particles of a given diameter (Otvos
J., 1999 and 2002).

\section{Data management and statistical analysis:}

Data are presented as the mean \pm SEM or as the change or percent change (mean \pm SEM) from baseline values. Baseline characteristics among the three groups were compared by one-way analysis of variance (ANOVA) for continuous variables and a chisquare test for categorical variables. Two-factor repeated measures ANOVA was performed to compare the average differences of egg consumption over time with egg substitute vs. egg vs. lutein fortified egg as between-subject factor and time as within-subject factor adjusting for gender, BMl, and age. Univariate and multivariate oneway ANCOVA were performed to compare mean differences in the change or percent change in plasma lipids and lipoprotein subfractions size and number with age, gender, and BMI as covariates. The least significant difference procedure was used for multiple pairwise comparisons. In order to test relationships between variables, Pearson and Spearman correlations were used when appropriate. Statistical analyses were performed by using SPSS (version 20) and a difference of $P<0.05$ was considered significant. 
Shymaa M. Ata.

\section{Results}

\section{Baseline characteristics of participants:}

The baseline characteristics of participants by group are shown in Table 1. Mean age was significantly different among groups $\left(F_{(2,30)}=6.65, P=0.004\right)$. Participants in the SUB group were significantly younger than those in the Egg-L group $(P=0.001)$. There were no overall significant differences in mean values across groups on other variables.

There was a significant difference in mean energy intake across groups $\left(F_{(2,30)}=3.32, P=0.050\right)$ (Table 2). Mean energy intake in the Egg group was significantly higher in comparison with the Egg-L group. After removing dietary intakes data of underreporters $(n=7)$ from the statistical analysis, the differences in mean energy intake became insignificant.

Energy intakes per kilogram body weight were also calculated to compare the means across groups. There was a significant difference in mean energy intake/kg among groups $\left(\mathrm{F}_{(2,30)}=6.35, P\right.$ $=0.005)$. After removing dietary intakes data of under-reporters $(n=$ 7) form the statistical analysis, there was a trend for significant difference in mean energy intakes per $\mathrm{kg}$ among groups $(P=0.09)$. Mean energy intake/kg at baseline was significantly lower in the Egg$\mathrm{L}$ group compared to both the SUB and Egg groups.

\section{Dietary intakes during the intervention:}

Multivariate repeated measures ANOVA were performed to compare dietary intakes among groups and over time. The set of dietary intakes variables was affected by group membership (Wilk's Lambda test: $\left(F_{(28,34)}=4.72, P=0.000\right)$. There was also an 


\section{Egyptian J. of Nutrition Vol. XXXV No. 2 (2020)}

interaction between diet and group membership (Wilk's Lambda test: $F(56,6)=5.88, P=0.02)$ which means some dietary components were increased over time while some were decreased. Mean dietary cholesterol $\left(\mathrm{F}_{(2,32)}=20.37, P=0.000\right)$, beta-carotene $\left(\mathrm{F}_{(2,32)}=3.79\right.$, $P=0.03)$, and lutein + zeaxanthin $\left(\mathrm{F}_{(2,32)}=7.17, P=0.003\right)$ were significantly different across groups (Table 3). Mean dietary cholesterol was significantly lower in the placebo group in comparison with both Egg and Egg-L groups $(P=0.000)$. For $\beta$ carotene, mean intake was significantly greater in the Egg-L compared to placebo $(P=0.03)$ and Egg groups $(P=0.02)$. In the same line, there was a significant difference in mean dietary lutein + zeaxanthin between placebo and Egg-L $(P=0.002)$ and between Egg and Egg-L $(P=0.005)$.

\section{Plasma lipids:}

Mean \pm SEM for plasma lipids variables at baseline, wk6, and wk12 are shown in Table 4. Because participants started with different baseline plasma lipids values, mean percent change from baseline was examined for plasma TC, LDL, HDL, and TG. Multivariate one-way analysis of covariance was used to compare mean percent changes across groups, with age, BMI, and gender as covariates (Fig. 1)

There was a trend for group assignment effect on mean \% change in plasma HDL-C $(F=2.73, P=0.08)$ and total cholesterol $(F$ $=3.08, P=0.06$ ) controlling for age. $\mathrm{HDL}$ was increased for all participants post intervention while total cholesterol slightly increased in the Egg group and decreased in both placebo and Egg-L groups. There was a treatment effect on only plasma cholesterol $(F=3.427$, $P=0.049$ ) for all participants after controlling for age, BMI, and gender. When only egg consumers included in this analysis, there 
Shymaa M. Ata.

was no significant change in any of plasma lipids variables post intervention controlling for gender and BMI. Age was not controlled as there was no significant difference in mean age between the Egg and Egg-L groups at baseline.

\section{Lipoprotein particles diameter:}

At baseline, there was a trend for significant difference in mean $\mathrm{HDL}$ average particle size among groups $(F=2.93, P=0.07)$. Participants in the Egg group started with lower HDL average particle size $(\mathrm{nm})$ than those in the placebo and Egg-L groups. Participants did not significantly differ in mean VLDL or LDL average particle sizes (Table 5).

There was a trend for an increase in LDL average particle size for all participants post-intervention $(F(2,30)=2.53, P=0.098)$ and HDL size $(F(2,30)=3.23, P=0.06)$ (Table 6).

There was a significant effect of treatment on change in HDL average particle size for all participants $(\mathrm{F}=3.976, P=0.03)$. There was no significant difference in mean change in $\mathrm{HDL}$ particle diameter between the Egg and Egg-L groups ( $P>0.05$, Independent samples t- test) (Table 7).

Changes in VLDL average particle size did not significantly correlate with changes in TG controlling for age, gender, and BMI $(r=$ $0.08, P=0.68)$. Changes in LDL average particle diameter also did not significantly correlate with change in TG/HDL-C ratio $(r=-0.31, P$ $=0.11$ ) controlling for age, BMI, and gender. However, changes in HDL average particle size positively associated with changes in serum HDL-C concentrations ( $r=0.55, P=0.003$ ) after controlling for the aforementioned covariates (Fig. 2). 
Egyptian J. of Nutrition Vol. XXXV No. 2 (2020)

\section{Lipoprotein particle concentrations ( $\mu \mathrm{mol} / \mathrm{L})$ :}

VLDL, LDL, and HDL subclasses concentration at baseline and the change from baseline are shown in Table8. Participants significantly differed in mean large VLDL particles concentration at baseline $(F=3.61, P=0.04)$. Egg group had the highest mean large VLDL concentration. There also was a trend for significant differences in mean total VLDL $(F=2.81, P=0.08)$ and small VLDL $(\mathrm{F}=2.49, P=0.10)$ particles concentration. Egg group had a higher total VLDL as compared to the placebo and Egg-L groups. For small VLDL particles concentration, the Egg-L group had higher concentrations in comparison with the placebo and Egg-L groups.

The change from baseline in total VLDL particles concentration was significant for all participants $(F=7.05, P=0.003)$. Total VLDL particles number was significantly decreased in the Egg- $L$ as compared to the Egg group $(P=0.005)$. Total VLDL particles concentration changed from $63.73 \pm 7.37$ at baseline to $45.28 \pm 7.53$ at wk12 in the Egg-L group as compared to $68.93 \pm 8.94$ at baseline and $68.88 \pm 11.84$ at wk12 in the Egg group. The changes in total VLDL particles number in the Egg-L group was also significantly greater than the changes in the placebo group $(P=0.01)$. Total VLDL particles number in the placebo group decreased from $43.79 \pm 7.53$ at baseline to $40.79 \pm 6.71$ at wk12 (Fig.3)

There change from baseline in small VLDL particles number was also significant across groups $(\mathrm{F}=5.89, P=0.01)$. The change was greater in the Egg-L in comparison with the placebo group $(P=$ $0.04)$ and Egg $(P=0.002)$ groups. The Egg-L group had a 0.75 fold decrease in small VLDL particles concentration (Table 8 (a), (Fig. 4). 
Shymaa M. Ata.

At baseline, there was a trend for significant difference in mean total LDL and large LDL particles number among groups $(F=$ 2.6, $P=0.09 ; \mathrm{F}=2.95, P=0.07$, respectively). The Egg group had the highest mean total LDL particles concentration while Egg-L had the highest mean large LDL particles number.

There was a trend for significant changes from baseline in total LDL across groups ( $F=2.96, P=0.07)$. Independent samples ttest among groups and the Egg and Egg-L groups showed a trend for significant changes from baseline in total LDL $(P=0.07)$. Total LDL particles number significantly decreased in the Egg-L group post intervention (Table 8 (b)).

Changes from baseline in large LDL and small LDL particles number were not significant across groups $(\mathrm{F}=0.61, P=0.55$ and $\mathrm{F}$ $=2.33, P=0.12$, respectively). Similarly, there was no significant changes from baseline in total IDL particles concentration across groups $(\mathrm{F}=0.18, P=0.84)$.

At baseline, participants differed significantly in mean Large HDL particles number $(F=3.61, P=0.04)$. There was a borderline significant difference in medium HDL particles concentration among groups $(\mathrm{F}=3.14, P=0.06)$.

There were not significant differences in mean change from baseline in HDL subclasses concentrations across groups ( $P>0.05$ ) controlling for age, gender, and BMI (Table 8 (C)).

At baseline, there were no significant differences in mean plasma apolipoproteins (ApoA-I, ApoA-II, ApoB, ApoC-II, ApoC-III, and apoE) across groups. Plasma apolipoproteins were not modified 
Egyptian J. of Nutrition Vol. XXXV No. 2 (2020)

either by diet or over time (Table9) However, changes in apoB from baseline associated with changes in total VLDL (rho $=0.33, P=0.06$ ) and total LDL (rho $=0.47, P=.006$ ).

\section{Discussion}

In this study, the mean percent change in plasma lipids was examined from baseline to assess the effects of egg feeding on these parameters. There was no significant effect of egg consumption on any of plasma lipids variables, in agreement with the studies by Goodrow et al., 2006 and Wenzel et al., 2006.

Furthermore, plasma LDL-C and HDL-C were favorably influenced by the egg-based dietary intervention (Fig. 1). The positive effects on plasma lipids variables can be explained in light fatty acids composition (Aguilera et al., 2001; Moreno et al., 2003). The percent of energy derived from fat increased over time from $34.43 \pm$ 1.30 at baseline to $36.50 \pm 1.57$ at wk12 in egg consumers. The intake of monounsaturated fatty acids (MUFA) expressed in $\mathrm{g} / \mathrm{d}$ was increased at wk12 from $23.72 \pm 1.68$ at baseline to $34.45 \pm 4.20$. On the other hand, the percent of energy from carbohydrate decreased from $46.50 \pm 1.75$ to $43.98 \pm 1.50$ at wk12. Eggs are good source of monounsaturated fatty acids. MUFA-enriched diets are commonly recommended for cardiovascular disease prevention (Lloyd-Jones et al., 2010).

HDL particles are diverse subpopulations classified based on their particle diameter, composition, and surface charge. These subpopulations vary widely among individuals with similar cholesterol concentration (El Harchaoui et al., 2009). There was a significant increase in HDL average particle size ( $\mathrm{nm})$ in egg consumers. 
Shymaa M. Ata.

Consistently with previous studies, changes in HDL size also associated positively with changes in serum HDL-C concentration (Arsenault et al., 2009). The increase in HDL particle average size can be explained by the observed increase, albeit non-significant, in large and medium HDL particle number after egg intervention (Greene et al., 2006). Large HDL particle numbers were associated with lower risk for CVD in women (Mora et al., 2009). The increase in HDL-C concentrations and average particle size would likely associate with an increase in reverse cholesterol transport (RCT) (Lund-Katz et al., 2010).

Moreover, subjects consumed lutein-fortified eggs showed a greater decrease in total and small VLDL as well as total LDL particle numbers compared to those consumed regular eggs. Total VLDL particle numbers have been shown to positively associate with incidence of CVD (Mora et al., 2009). Higher total LDL particle numbers were also positively associated with the incidence of coronary heart disease in women, age $\geq 65 y$, from the Cardiovascular Health Study (Kullar et al., 2002). Changes in apoB concentrations were associated positively with changes in total VLDL and LDL particle numbers, in agreement with previous reports (Sniderman et al., 1991). ApoB concentration is a strong indicator of LDL particle numbers and closely equal in predicting CVD risk (Cole et al., 2013).

ApoA-1 is a main protein component of $\mathrm{HDL}$ and a key player in reverse cholesterol transport. The present study showed that serum apoA-1 concentration did not significantly change in either group after 12-wk. In agreement, serum apoA-1 concentration did not change in response to egg treatment $(100 \mathrm{~g}$ of liquid $\sim 2$ whole egg vs. $100 \mathrm{~g}$ of yolk free eggs per day in frozen breakfast meals) in 
Egyptian J. of Nutrition Vol. XXXV No. 2 (2020)

overweight, postmenopausal women during the 14-wk crossover dietary trial (Sawrey-Kubicek et al., 2019). In the same line, serum apo-A-1 did not change in older adults with early macular degeneration after consuming 12 eggs per week for 1 year (Aljohi et al., 2019).

One of the strengths of the present study is that it is a free living study and followed a weight maintenance protocol. Furthermore, the present study dietary intervention of only one egg per day in the context of a regular diet was easily adaptable and likely promoted adherence as well as dietary compliance. There are certain limitations of the current study that should be also considered. First, the study sample composed mainly of women that are employees at the University of Connecticut, which affects the degree of extrapolation of the study results to general populations. Second, dietary data were self-reported which rule in a possibility for recall bias and error.

In conclusion, despite the concerns associated with egg containing diets, this study demonstrates that moderate egg consumption actually promotes favorable lipid and lipoprotein subfraction profiles. Moderate egg consumption warrants further consideration to satisfy essential dietary requirements for at risk CVD populations. Further studies with larger sample sizes should continue to explore eggs' beneficial effects on lipid and lipoprotein subfraction profiles. 
Shymaa M. Ata.

Table 1. Baseline descriptive statistics of study sample $(\mathrm{N}=33)$

\begin{tabular}{l|c|c|c}
\hline & $\begin{array}{c}\text { SUB }(\mathrm{n}=12,10 \text { females } \\
\text { and } 2 \text { males })\end{array}$ & $\begin{array}{c}\text { Egg }(\mathrm{n}=10,8 \text { females } \\
\text { and 2males })\end{array}$ & $\begin{array}{c}\text { Egg-L }(\mathrm{n}=11,7 \\
\text { females and 4 males })\end{array}$ \\
\hline Age $(\mathrm{y})$ & $49.25^{\mathrm{a}} \pm 1.75$ & $55^{\mathrm{ab}} \pm 2.62$ & $61.36^{\mathrm{b}} \pm 2.83$ \\
\hline $\mathrm{WC}(\mathrm{cm})$ & $82.77 \pm 2.70$ & $90.08 \pm 3.47$ & $89.09 \pm 3.40$ \\
\hline $\mathrm{BMl}\left(\mathrm{Kg} / \mathrm{m}^{2}\right)$ & $24.61 \pm 1.31$ & $26.17 \pm 1.35$ & $25.24 \pm 0.84$ \\
\hline $\mathrm{LDL}-\mathrm{c}(\mathrm{mg} / \mathrm{dl})$ & $133.25 \pm 12.25$ & $131.48 \pm 7.61$ & $159.39 \pm 9.27$ \\
\hline $\mathrm{HDL}-\mathrm{c}(\mathrm{mg} / \mathrm{dl})$ & $64.4 \pm 5.01$ & $49.53 \pm 3.19$ & $57.2 \pm 4.87$ \\
\hline $\mathrm{TC}(\mathrm{mg} / \mathrm{dl})$ & $213.74 \pm 12.60$ & $206.47 \pm 7.67$ & $236.22 \pm 12.02$ \\
\hline $\mathrm{TG}(\mathrm{mg} / \mathrm{dl})$ & $80.47 \pm 6.87$ & $107.56 \pm 10.75$ & $98.12 \pm 10.39$ \\
\hline $\mathrm{BP}(\mathrm{mmHg})$ & $116.5 \pm 3.46$ & $115.1 \pm 3.39$ & $123.91 \pm 3.42$ \\
Systolic Diastolic & $74.42 \pm 2.24$ & $73.4 \pm 2.27$ & $77.45 \pm 2.31$ \\
\hline Valus are man
\end{tabular}

Values are mean \pm SEM. One-way analysis of Variance was used to test mean differences. Means in a row with superscripts without a common letter differ, $P<0.05$.

Table2. Baseline dietary intakes for all participants divided by group

\begin{tabular}{l|c|c|c}
\hline \multirow{2}{*}{ Energy intake (Kcal) } & SUB $(\mathrm{n}=12)$ & EGG $(\mathrm{n}=10)$ & EGG-L $(\mathrm{n}=11)$ \\
\cline { 2 - 4 } & $\begin{array}{c}1956.17 \pm 189.29^{\mathrm{ab}} \\
13.08 \pm 1.18^{\mathrm{a}}\end{array}$ & $\begin{array}{c}2063.4 \pm 127.69^{\mathrm{a}} \\
12.86 \pm 0.85^{\mathrm{ac}}\end{array}$ & $\begin{array}{c}1515.82 \pm 135.67^{\mathrm{b}} \\
9.17 \pm 0.59^{\mathrm{b}}\end{array}$ \\
\hline Fat $(\%)$ & $32.22 \pm 1.16$ & $32.97 \pm 1.85$ & $35.76 \pm 1.81$ \\
\hline Protein (\%) & $15.41 \pm 1.16$ & $15.35 \pm 0.61$ & $17.02 \pm 1.16$ \\
\hline CHO (\%) & $48.08 \pm 1,78$ & $49.11 \pm 2.57$ & $44.13 \pm 2.27$ \\
\hline Alcohol (g) & $4.30 \pm 1.45$ & $2.58 \pm 0.79$ & $3.07 \pm 1.56$ \\
\hline Cholesterol (mg) & $185.75 \pm 22.64$ & $259.95 \pm 40.16$ & $202.73 \pm 16.69$ \\
\hline SFA (g) & $23.34 \pm 3.14$ & $28.03 \pm 3.13$ & $20.04 \pm 1.97$ \\
\hline Mono $(g)$ & $26.39 \pm 3.46$ & $27.00 \pm 2.17$ & $20.75 \pm 2.25$ \\
\hline PUFA (g) & $17.44 \pm 2.29$ & $15.81 \pm 1.23$ & $16.76 \pm 3.88$ \\
\hline Fiber (g) & $22.02 \pm 2.30$ & $22.71 \pm 2.54$ & $20.25 \pm 2.54$ \\
\hline Beta-carotene (mcg) & $3544.08 \pm 765.30$ & $4302 \pm 632.19$ & $4943.18 \pm 680.01$ \\
\hline Alpha-carotene(mcg) & $615.03 \pm 179.60$ & $925.2 \pm 298.11$ & $1005.77 \pm 371.67$ \\
\hline Beta criptoxanthin(mcg) & $239.92 \pm 50.26$ & $147.7 \pm 41.71$ & $264.00 \pm 53.12$ \\
\hline Lutein \& zeaxanthin (mcg) & $2095.33 \pm 373.93$ & $1741.1 \pm 216.15$ & $1270.64 \pm 398.18$ \\
\hline Lycopene (mcg) & $8618.92 \pm 1502.29$ & $4995 \pm 996.12$ & $7190.82 \pm 1492.71$ \\
\hline Valus are mean \pm sEM.
\end{tabular}

Values are mean \pm SEM. Means in a row with superscripts without a common letter differ, $P<0.05$.

Multivariate one-way ANOVA was used to compare dietary intakes across groups at baseline 
Egyptian J. of Nutrition Vol. XXXV No. 2 (2020)

Table3. Dietary intakes at baseline, wk6, and wk12

\begin{tabular}{|c|c|c|c|c|c|c|}
\hline & $\mathrm{BL}$ & & Wk.6 & & Wk.12 & \\
\hline & & & Mean \pm SE & & & \\
\hline \multicolumn{7}{|c|}{ Energy (Kcal) } \\
\hline Placebo & 1956.17 & 189.29 & 1926.17 & 215.04 & 1814.67 & 128.17 \\
\hline Egg & 2063.40 & 127.69 & 1749.10 & 212.35 & 2029.40 & 256.26 \\
\hline Egg-L & 1515.82 & 129.90 & 2099.64 & 168.10 & 2070.91 & 244.63 \\
\hline \multicolumn{7}{|l|}{ Fat (\%) } \\
\hline Placebo & 32.22 & 1.16 & 32.90 & 2.24 & 36.54 & 2.00 \\
\hline Egg & 32.97 & 1.85 & 35.58 & 1.36 & 37.46 & 2.17 \\
\hline Egg-L & 35.76 & 1.81 & 35.13 & 2.82 & 35.62 & 2.31 \\
\hline \multicolumn{7}{|c|}{ Protein (\%) } \\
\hline placebo & 15.41 & 1.16 & 16.04 & 1.32 & 15.33 & 1.13 \\
\hline Egg & 15.35 & 0.61 & 17.89 & 1.24 & 17.90 & 1.40 \\
\hline Egg-L & 17.02 & 1.16 & 16.64 & 1.16 & 17.60 & 1.09 \\
\hline \multicolumn{7}{|c|}{ Carbohydrate (\%) } \\
\hline Placebo & 48.08 & 1.78 & 47.87 & 2.24 & 44.15 & 1.56 \\
\hline Egg & 49.11 & 2.57 & 44.25 & 1.54 & 43.51 & 2.44 \\
\hline Egg-L & 44.13 & 1.28 & 45.17 & 2.99 & 44.41 & 1.92 \\
\hline \multicolumn{7}{|c|}{ Cholesterol (mg) } \\
\hline Placebo & 185.75 & 22.64 & 176.28 & 23.94 & $164.66^{\mathrm{a}}$ & 20.02 \\
\hline Egg & 259.95 & 40.16 & 348.67 & 33.39 & $430.99^{b}$ & 37.86 \\
\hline Egg-L & 202.73 & 16.69 & 398.99 & 26.19 & $379.22^{b}$ & 23.73 \\
\hline \multicolumn{7}{|l|}{ SFA (g) } \\
\hline Placebo & 23.34 & 3.14 & 25.32 & 4.04 & 25.29 & 2.65 \\
\hline Egg & 28.03 & 3.13 & 28.15 & 4.85 & 32.76 & 5.56 \\
\hline Egg-L & 20.04 & 1.97 & 25.89 & 2.61 & 26.47 & 3.68 \\
\hline \multicolumn{7}{|l|}{ Mono (g) } \\
\hline Placebo & 26.39 & 3.46 & 25.11 & 2.59 & 27.52 & 2.39 \\
\hline Egg & 27.00 & 2.17 & 27.87 & 3.73 & 33.01 & 4.84 \\
\hline Egg-L & 20.75 & 2.25 & 34.31 & 5.82 & 35.76 & 6.92 \\
\hline \multicolumn{7}{|l|}{ PUFA (g) } \\
\hline Placebo & 17.44 & 2.29 & 16.18 & 2.06 & 16.94 & 1.91 \\
\hline Egg & 15.81 & 1.23 & 11.89 & 1.16 & 14.39 & 2.30 \\
\hline Egg-L & 16.76 & 3.88 & 19.33 & 3.21 & 21.05 & 4.44 \\
\hline \multicolumn{7}{|l|}{ Fiber $(\mathrm{g})$} \\
\hline Placebo & 22.02 & 2.30 & 21.44 & 1.83 & 21.51 & 1.72 \\
\hline Egg & 22.71 & 2.54 & 19.76 & 3.42 & 17.91 & 2.18 \\
\hline Egg-L & 20.25 & 1.38 & 25.69 & 2.31 & 25.56 & 2.85 \\
\hline \multicolumn{7}{|c|}{$\begin{array}{l}\text { beta-carotene } \\
(\mathrm{mcg})\end{array}$} \\
\hline placebo & 3544.08 & 765.30 & 2788.33 & 439.74 & $3393.33^{a}$ & 743.89 \\
\hline Egg & 4302.00 & 632.19 & 2754.40 & 371.50 & $1706.60^{\mathrm{ac}}$ & 393.29 \\
\hline Egg-L & 4943.18 & 680.01 & 4484.09 & 644.64 & $5997.82^{b}$ & 1431.19 \\
\hline $\begin{array}{l}\text { alpha-car } \\
\text { (mcg) }\end{array}$ & & & & & & \\
\hline
\end{tabular}


Shymaa M. Ata.

\section{Continue}

\begin{tabular}{l|c|c|c|c|c|c}
\hline placebo & 615.03 & 179.60 & 495.58 & 124.75 & 340.50 & 128.52 \\
\hline Egg & 925.20 & 298.11 & 461.40 & 137.95 & 404.80 & 98.26 \\
\hline Egg-L & 1005.77 & 371.67 & 726 & 252.46 & 1125.18 & 442.69 \\
\hline $\begin{array}{l}\beta \text { - criptoxanthin } \\
\text { (mcg) }\end{array}$ & & & & & & \\
\hline Placebo & 189.83 & 54.96 & 120.25 & 35.88 & 139.17 & 43.81 \\
\hline Egg & 198.30 & 49.26 & 134.60 & 20.93 & 110.30 & 27.80 \\
\hline Egg-L & 272.64 & 44.26 & 252 & 40.11 & 213.45 & 37.35 \\
\hline $\begin{array}{l}\text { Lutein \& } \\
\text { zeaxanthin (mcg) }\end{array}$ & 2064.50 & 438.20 & 1578.68 & 379.58 & $1505.17^{\mathrm{a}}$ & 395.03 \\
\hline Placebo & 2188.40 & 236.26 & 1629.70 & 398.46 & $1907.50^{\mathrm{ac}}$ & 428.23 \\
\hline Egg & 2010.64 & 398.18 & 4361.73 & 866.02 & $4354.82^{\mathrm{b}}$ & 1032.35 \\
\hline Egg-L & & & & & & \\
\hline Lycopene (mcg) & & & & & & \\
\hline placebo & 7734.67 & 1460.84 & 8049.67 & 2346.26 & 6042.67 & 1142.26 \\
\hline Egg & 5557.40 & 798.37 & 5038.80 & 1634.30 & 4471.20 & 2713.78 \\
\hline Egg-L & 7644.18 & 1741.08 & 3974.82 & 1073.80 & 3821.82 & 1056.90 \\
\hline
\end{tabular}

$\mathrm{KJ}=0.239 \mathrm{Kcal}$. Multivariate repeated measures ANOVA was used to test differences in dietary intakes over time and among groups. Means in a row with superscripts without a common letter differ, $P<0.05$. 
Egyptian J. of Nutrition Vol. XXXV No. 2 (2020)

Table 4. Mean \pm SEM for plasma lipids at baseline, wk 6 , and wk 12

\begin{tabular}{l|l|l|l}
\hline Variable & Baseline & Week 6 & Week 12 \\
\hline $\begin{array}{l}\text { Total Cholesterol (mg/dl) } \\
\text { SUB }\end{array}$ & & & \\
EGG & $213.74 \pm 12.60$ & $206.10 \pm 11.12$ & $200.37 \pm 10.32$ \\
EGG-L & $206.47 \pm 7.67$ & $210.35 \pm 9.18$ & $208.45 \pm 7.89$ \\
& $236.22 \pm 12.02$ & $230.10 \pm 11.72$ & $229.71 \pm 11.26$ \\
\hline LDL-C (mg/dl) & & & \\
SUB & $133.25 \pm 12.25$ & $122.46 \pm 10.47$ & $119.96 \pm 9.99$ \\
EGG & $131.48 \pm 7.61$ & $133.37 \pm 10.61$ & $126.65 \pm 7.16$ \\
EGG-L & $159.39 \pm 9.27$ & $155.48 \pm 10.05$ & $151.59 \pm 9.24$ \\
\hline HDL-C (mg/dl) & & & \\
SUB & $61.80 \pm 4.49$ & $63.96 \pm 3.71$ & $62.05 \pm 3.85$ \\
EGG & $49.53 \pm 3.19$ & $52.15 \pm 2.90$ & $56.21 \pm 3.98$ \\
EGG-L & $57.12 \pm 5.13$ & $60.10 \pm 4.84$ & $61.89 \pm 4.62$ \\
\hline Triglycerides (mg/dl) & & & \\
SUB & $80.47 \pm 6.87$ & $83.88 \pm 7.75$ & $76.42 \pm 7.90$ \\
EGG $(\mathrm{n}=9)$ & $107.56 \pm 10.75$ & $107.51 \pm 11.72$ & $107.94 \pm 10.59$ \\
EGG-L & $98.12 \pm 10.39$ & $77.65 \pm 8.00$ & $82.00 \pm 7.80$ \\
\hline Vals aremean \pm SEM. & & & \\
\hline
\end{tabular}

Values are mean \pm SEM. Repeated measures ANOVA adjusting for BMI, gender, and age.

Table5. Baseline VLDL, LDL, and HDL average particle sizes (nm)

\begin{tabular}{l|c|c|c}
\hline & VLDL size & LDL size & HDL size \\
\hline Placebo $(n=12)$ & $48.03 \pm 1.99$ & $21.48 \pm 0.17$ & $9.38 \pm 0.14^{\mathrm{a}}$ \\
\hline Egg $\quad(n=10)$ & $48.18 \pm 2.26$ & $21 \pm 0.31$ & $8.87 \pm 0.14^{\mathrm{b}}$ \\
\hline Egg-L $(n=11)$ & $45.64 \pm 1.54$ & $21.48 \pm 0.21$ & $9.25 \pm 0.17^{\mathrm{ac}}$ \\
\hline
\end{tabular}

Values are means \pm SEM. One-way ANOVA, $P<0.05$ is statistically significant. 
Shymaa M. Ata.

Table 6. VLDL, LDL, and HDL average particle sizes for all participants at baseline and after 12 weeks of egg intervention

\begin{tabular}{l|c|c|c}
\hline & Placebo $(n=12)$ & Egg $(n=10)$ & Egg-L $(n=11)$ \\
\hline VLDL size & & & \\
\hline Baseline & $48.03 \pm 1.99$ & $48.18 \pm 2.26$ & $45.64 \pm 1.54$ \\
\hline Wk12 & $49.1 \pm 1.81$ & $50.12 \pm 2.24$ & $48.15 \pm 1.53$ \\
\hline LDL size & & & \\
\hline Baseline & $21.48 \pm 0.17$ & $21 \pm 0.31$ & $21.48 \pm 0.21$ \\
\hline Wk12 & $21.6 \pm 0.21$ & $21.12 \pm 0.30$ & $21.85 \pm 0.20$ \\
\hline HDL size & $9.38 \pm 0.14$ & & \\
\hline Baseline & $9.36 \pm 0.11$ & $8.87 \pm 0.14$ & $9.25 \pm 0.17$ \\
\hline Wk12 & & $8.95 \pm 0.18$ & $9.39 \pm 0.18$ \\
\hline Values are mean \pm SEM. Multivariate repeated measures ANOVA
\end{tabular}

Table 7. Change from baseline in lipoprotein particles diameter (nm)

\begin{tabular}{l|c|c|c}
\hline & \multicolumn{3}{|c}{ Mean \pm SEM } \\
\hline Placebo $(\mathrm{n}=12)$ & VLDL size & LDL size & HDL size \\
\hline Egg $(\mathrm{n}=10)$ & $1.07 \pm 1.86$ & $0.12 \pm 0.13$ & $-0.03 \pm 0.04$ \\
\hline Egg-L $(\mathrm{n}=11)$ & $1.94 \pm 1.42$ & $0.12 \pm 0.13$ & $0.08 \pm 0.07$ \\
\hline
\end{tabular}

Mean \pm SEM. Multivariate analysis of covariance with age, BMl, and gender as covariates, $\mathrm{P}<0.05$ is statistically significant. 
Egyptian J. of Nutrition Vol. XXXV No. 2 (2020)

Table 8. (a) Serum VLDL subclasses concentrations and the change from baseline

\begin{tabular}{|c|c|c|c|}
\hline Baseline & Mean & SEM & Change \\
\hline \multicolumn{4}{|c|}{ Total VLDL } \\
\hline Placebo & 43.79 & 7.53 & -3.00 \\
\hline Egg & 68.93 & 8.94 & -0.05 \\
\hline Egg-L & 63.73 & 7.73 & -18.45 \\
\hline \multicolumn{4}{|c|}{ Large VLDL } \\
\hline Placebo & 0.72 & 0.20 & 0.07 \\
\hline Egg & 3.56 & 1.49 & -0.38 \\
\hline Egg-L & 1.00 & 0.27 & -0.19 \\
\hline \multicolumn{4}{|c|}{ Medium VLDL } \\
\hline Placebo & 17.98 & 3.60 & -3.04 \\
\hline Egg & 28.25 & 6.71 & -1.66 \\
\hline Egg-L & 22.94 & 5.07 & -4.38 \\
\hline \multicolumn{4}{|c|}{ Small VLDL } \\
\hline Placebo & 25.88 & 4.97 & -0.43 \\
\hline Egg & 34.70 & 3.76 & 5.24 \\
\hline Egg-L & 39.20 & 4.13 & -9.73 \\
\hline
\end{tabular}

Mean \pm SEM. One-way ANOVA was used to compare means across groups at baseline. Analysis of covariance was used to compare mean changes from baseline, with age, gender, and $\mathrm{BMI}$ as covariates. $P<0.05$ is statistically significant. 
Shymaa M. Ata.

Table8 (b) Serum LDL subclasses concentrations and the change from baseline

\begin{tabular}{l|c|c|c}
\hline \multicolumn{2}{c|}{ Mean } & SEM & Change \\
\hline \multicolumn{1}{l|}{ Total LDL $(\mu \mathrm{mol} / \mathrm{L})$} & & 77.12 & -3.25 \\
\hline Placebo & 911.42 & 152.98 & 49.3 \\
\hline Egg & 1217.7 & 80.69 & -131.18 \\
\hline Egg-L & 1182.82 & & -6.25 \\
\hline Total IDL & & 13.63 & -4.5 \\
\hline Placebo & 36.25 & 21.17 & -13.91 \\
\hline Egg & 56.8 & 10.81 & \\
\hline Egg-L & 39.27 & & 47.75 \\
\hline Large LDL & & 57.77 & 78.6 \\
\hline Placebo & 434.58 & 58.93 & 82.73 \\
\hline Egg & 368.9 & 55.21 & \\
\hline Egg-L & 565.82 & & -44.5 \\
\hline Small LDL & & 70.97 & -24.5 \\
\hline Placebo & 440.42 & 170.08 & -200.36 \\
\hline Egg & 791.8 & 115.02 & \\
\hline Egg-L & 577.82 & . & \\
\hline Mean \pm SEM. One-way & AN & & \\
\hline
\end{tabular}

Mean \pm SEM. One-way ANOVA was used to compare means across groups at baseline. Analysis of covariance was used to compare mean changes from baseline, with age, gender, and BMI as covariates. $P<0.05$ is statistically significant. 
Egyptian J. of Nutrition Vol. XXXV No. 2 (2020)

Table 8 (C) Serum HDL subclasses concentration and the change from baseline

\begin{tabular}{|c|c|c|c|}
\hline Baseline & Mean & SEM & Change \\
\hline \multicolumn{4}{|c|}{ Total HDL $(\mu \mathrm{mol} / \mathrm{L})$} \\
\hline Placebo & 32.88 & 1.74 & 1.3 \\
\hline Egg & 34.69 & 1.83 & -1.61 \\
\hline Egg-L & 30.81 & 1.26 & -0.16 \\
\hline \multicolumn{4}{|l|}{ Large } \\
\hline Placebo & 11.11 & 1.53 & -0.34 \\
\hline Egg & 5.98 & 0.98 & 0.63 \\
\hline Egg-L & 9.3 & 1.38 & 0.55 \\
\hline \multicolumn{4}{|l|}{ Medium } \\
\hline Placebo & 4.36 & 1.11 & 1.03 \\
\hline Egg & 5.19 & 1.26 & 1.14 \\
\hline Egg-L & 1.5 & 0.84 & -0.51 \\
\hline \multicolumn{4}{|l|}{ Small HDL } \\
\hline Placebo & 18.38 & 2.31 & -0.28 \\
\hline Egg & 23.54 & 2.01 & -3.23 \\
\hline Egg-L & 20 & 1.26 & -0.19 \\
\hline
\end{tabular}

Mean \pm SEM. One-way ANOVA 
Shymaa M. Ata.

Table 9 Plasma apolipoproteins at baseline and after the 12 wk. intervention

\begin{tabular}{|c|c|c|c|c|c|c|c|c|}
\hline Apo A-I & Baseline & SEM & W12 & SEM & Change & $\begin{array}{l}P \\
\text { (time) }\end{array}$ & $\begin{array}{l}P \\
\text { (group) }\end{array}$ & $\begin{array}{l}\boldsymbol{P} \\
\text { interaction }\end{array}$ \\
\hline Placebo & 1557 & 89.51 & 1568.75 & 70.06 & 12 & NS & NS & NS \\
\hline Egg & 1433.2 & 75.42 & 1390.9 & 71.45 & -42 & & & \\
\hline Egg-L & 1480.45 & 90.28 & 1385.45 & 76.08 & -95 & & & \\
\hline \multicolumn{9}{|l|}{ ApoA-II } \\
\hline Placebo & 169.65 & 13.19 & 176 & 11.12 & 6.35 & NS & NS & NS \\
\hline Egg & 166.9 & 13.70 & 149.47 & 15.64 & -17.44 & & & \\
\hline Egg-L & 164.14 & 10.36 & 157.68 & 8.68 & -6.45 & & & \\
\hline \multicolumn{9}{|l|}{ ApoB } \\
\hline Placebo & 999.92 & 120.49 & 959.33 & 151.02 & -40.58 & NS & NS & NS \\
\hline Egg & 1291.2 & 185.46 & 1100.95 & 102.66 & -190.25 & & & \\
\hline Egg-L & 1156.36 & 88.19 & 1020.32 & 77.40 & -136.05 & & & \\
\hline \multicolumn{9}{|l|}{ ApoC-II } \\
\hline Placebo & 71.85 & 9.00 & 66.33 & 7.20 & -5.52 & NS & NS & NS \\
\hline Egg & 76.71 & 7.00 & 74.17 & 9.84 & -2.54 & & & \\
\hline Egg-L & 80.62 & 9.12 & 73.22 & 8.14 & -7.40 & & & \\
\hline \multicolumn{9}{|l|}{ ApoCIII } \\
\hline Placebo & 225.42 & 19.59 & 221.38 & 19.53 & -4.04 & NS & NS & NS \\
\hline Egg & 250.95 & 26.73 & 250.3 & 40.20 & -0.65 & & & \\
\hline Egg-L & 244.95 & 24.31 & 220.27 & 23.45 & -24.68 & & & \\
\hline \multicolumn{9}{|l|}{ ApoE } \\
\hline Placebo & 53.47 & 4.50 & 56.45 & 4.51 & 2.98 & NS & NS & NS \\
\hline Egg & 58.73 & 4.69 & 59.05 & 3.92 & 0.32 & & & \\
\hline Egg-L & 61.66 & 5.22 & 64.83 & 4.09 & 3.17 & & & \\
\hline
\end{tabular}

Values are mean \pm SEM. P-values are for time, treatment, and time $x$ treatment interactions for all participants analyzed using two-way repeated measures ANOVA and adjusting for age, BMl, and sex. NS, not significant $(P>0.05)$ 
Egyptian J. of Nutrition Vol. XXXV No. 2 (2020)

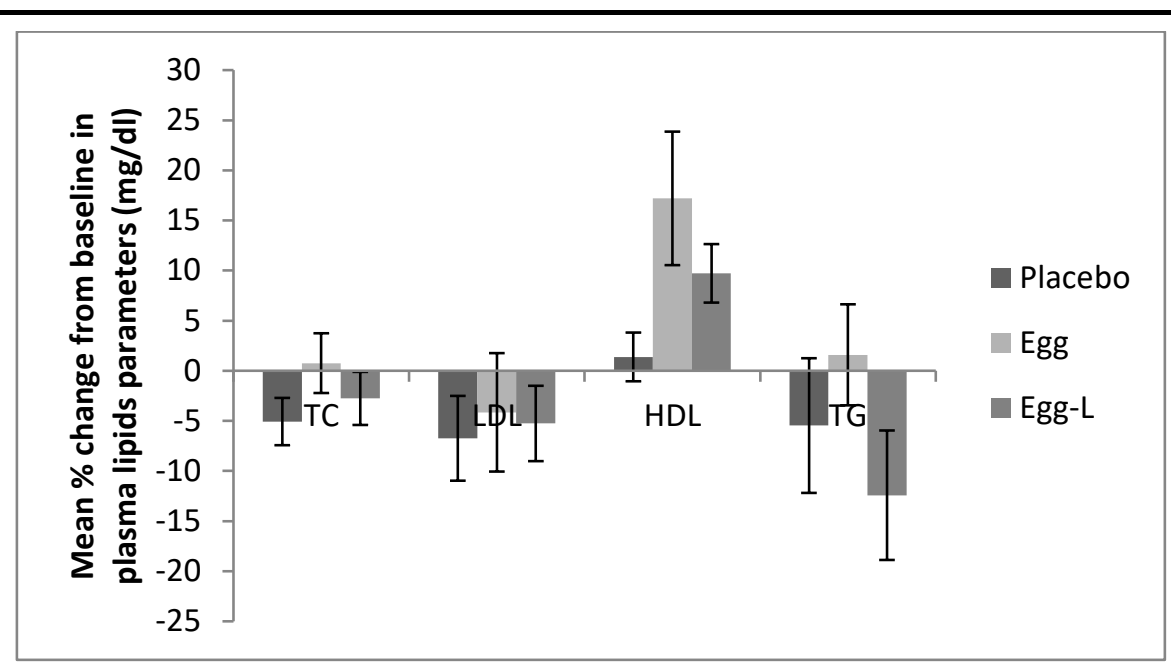

Figure 1 Mean \% change from baseline in plasma lipids $(\mathrm{mg} / \mathrm{dl})$

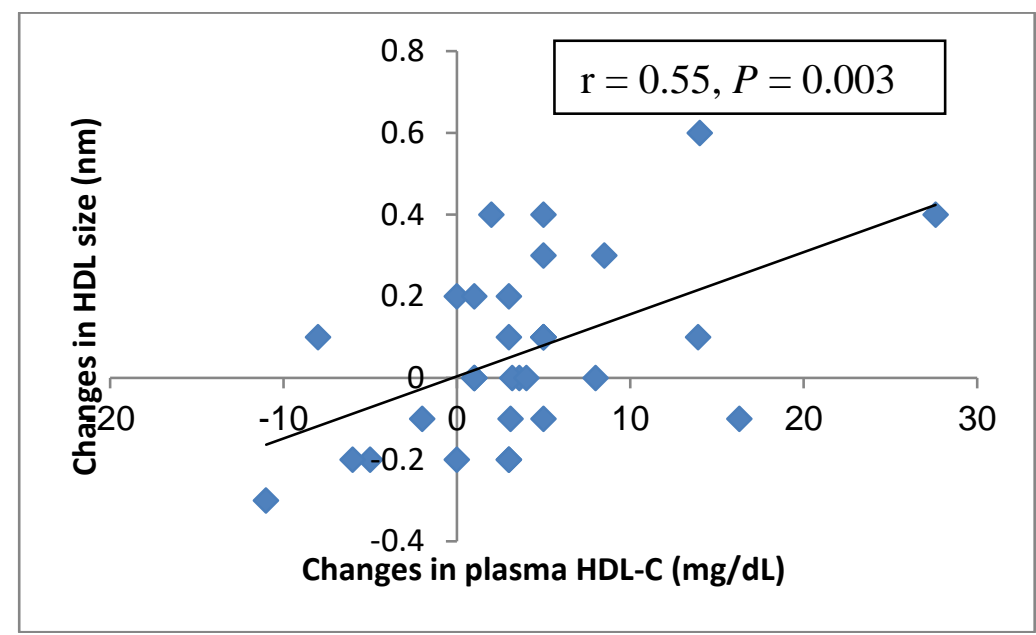

Figure 2 Correlation between changes from baseline in plasma HDL-C concentrations and changes in HDL average particle size 
Shymaa M. Ata.

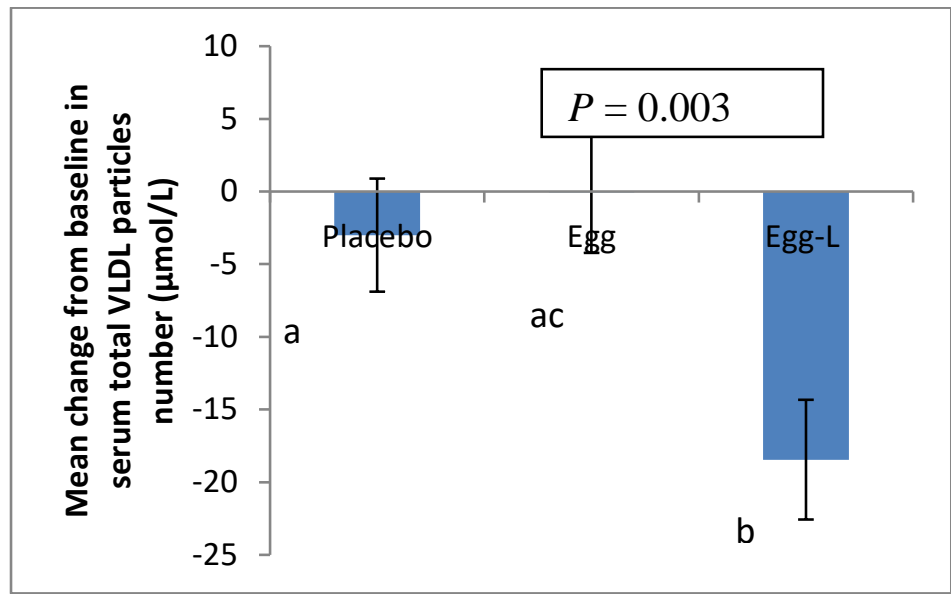

Figure 3 Change from baseline in total VLDL particles concentration $(\mu \mathrm{mol} / \mathrm{L})$

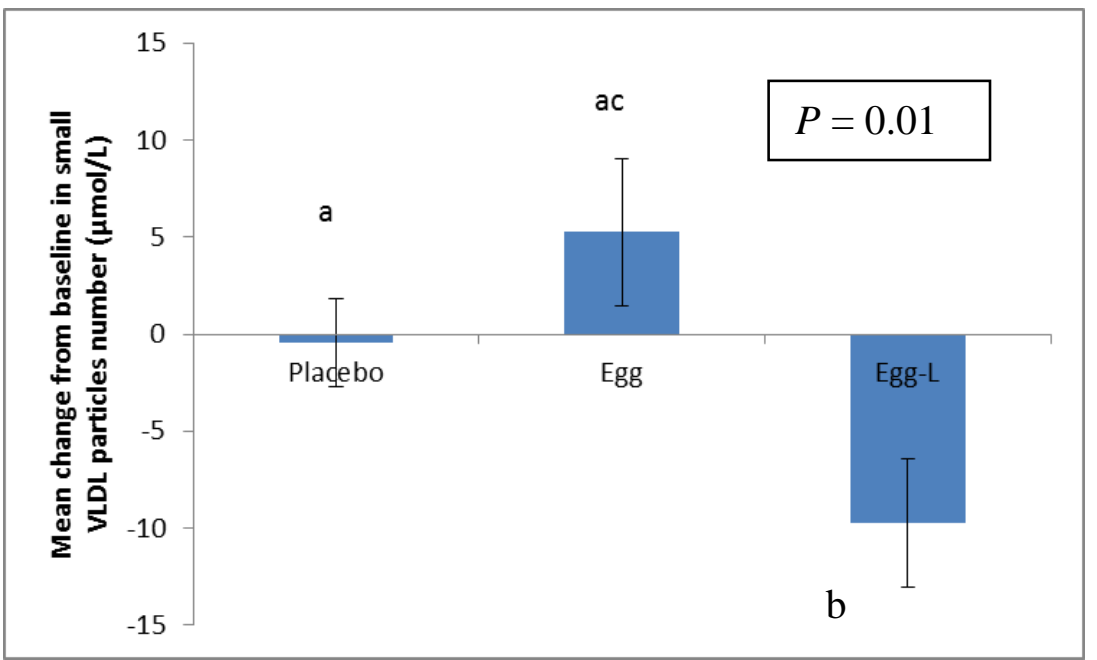

Figure 4 Change from baseline in small VLDL particles concentrations ( $\mu \mathrm{mol} / \mathrm{L}$ ) 
Egyptian J. of Nutrition Vol. XXXV No. 2 (2020)

\section{References}

Aguilera CM, Ramirez-Tortosa MC, Mesa MD, Gil A (2001).

Protective effect of monounsaturated and polyunsaturated fatty acids on the development of cardiovascular disease. Nutr Hosp ;16:78-91.

Aljoho H, Dopler-Nelson M, Cifuentes M, Wilson TA (2019).

The consumption of 12 Eggs per week for 1 year does not alter fasting serum markers of cardiovascular disease in older adults with early macular degeneration. Journal of Nutrition \& Intermediary Metabolism ; 15: 35-41

Allain CC, Poon LS, Chan CS, Richmond W, Fu PC (1974).

Enzymatic determination of total serum cholesterol. Clin Chem ;20:470-5.

Arsenault BJ, Lemieux I, Despres JP, Gagnon P, Wareham NJ, Stroes E, Kastelein J, Khaw K, Boekholdt SM (2009).

HDL particle size and the risk of coronary heart disease in apparently healthy men and women: the EPIC-Norfolk prospective population study. Atherosclerosis; 206:276-81.

Carr TP, Andresen CJ, Rudel LL (1993).

Enzymatic determination of triglyceride, free cholesterol, and total cholesterol in tissue lipid extracts. Clin Biochem; 26:3942. 
Shymaa M. Ata.

Carmena R, Duriez P, and Fruchart J (2004).

Atherogenic Lipoprotein Particles in Atherosclerosis. Circulation ; Volume 109, Issue 23_suppl_1, 15 June , Pages III-2-III-7

Cole TG, Contois JH, Csako G, McConnel JP, Remaley AT, Devaraj S, Hoefner DM, Mallory T, Sethi AA, Warnick GR. (2013).

Association of Apolipoprotein B and Nuclear Magnetic Resonance Spectroscopy-Derived LDL Particle Number with Outcomes in 25 Clinical Studies: Assessment by the AACC Lipoprotein and Vascular Diseases Division Working Group on Best Practices. Clin Chem.; 59(5):752-70

Corsetti JP, Zareba W, Moss AJ, Sparks CE (2004).

Apolipoprotein $B$ determines risk for recurrent coronary events in post infarction patients with metabolic syndrome. Atherosclerosis. ; 177:367-373.

Davidson MH. (2009).

Apolipoprotein measurements: is more widespread use clinically indicated? Clin. Cardiol. ; 32, 9, 482-486

El Harchaoui K, Arsenault BJ, Franssen R, Despres JP, Hovingh GK, Stores E, Otvos JD, Wareham NJ, Kastelein JJ, Khaw K, Boekholdt SM. (2009).

High-density lipoprotein particle size and concentration and coronary risk. Ann Intern Med ;150:84-93. 
Egyptian J. of Nutrition Vol. XXXV No. 2 (2020)

Feingold KR \& Grunfeld C. (2018)

Introduction to lipids and lipoproteins. Endotext-NCBI Bookshelf.

Friedewald WT, Levy RI, Fredrickson DS (1972).

Estimation of the concentration of low-density lipoprotein cholesterol in plasma, without use of the preparative ultracentrifuge. Clin Chem ;18:499-502.

Goodrow EF, Wilson TA, Houde SC, Vishwanathan R, Patrick AS, Handelman G, Nicolosi RJ. (2006).

Consumption of one egg per day increases serum lutein and zeaxanthin concentrations in older adults without altering serum lipid and lipoprotein cholesterol concentrations. J Nutr; 136:2519-24.

Greene CM, Waters D, Clark RM, Contois JH, Fernandez ML (2006).

Plasma LDL and HDL characteristics and carotenoid content are positively influenced by egg consumption in an elderly population. Nutr Metab (Lond; 3:6

Ivanova EA, Myasoedova VA, Melnichenko AA, Grechko AV, and Orekhov AN (2017).

Small Dense Low-Density Lipoprotein as Biomarker for Atherosclerotic Diseases. Oxidative Medicine and Cellular Longevity. Article ID 1273042 
Shymaa M. Ata.

Kaneva AM, Potolitsyna NN, Bojko ER, Odland JO (2015).

The Apolipoprotein B/Apolipoprotein A-1 Ratio as a Potential Marker of Plasma Atherogenisity. Disease Markers. Article ID 591454.

Kosmas CE, Martinez I, Sourlas A, Bouza KV, Campos FN, Torres V, Montan PD, Guzman E. (2018).

High- Density lipoprotein (HDL) functionality and its relevance to atherosclerotic cardiovascular disease. Drugs in Context ; 7: 212525 .

Kuller L, Arnold A, Tracy R,Otvos J, Burke G, Psaty B, Siscovick D, Freedman DS, Kronmal R. (2002).

Nuclear magnetic resonance spectroscopy of lipoproteins and risk of coronary heart disease in the cardiovascular health study. Arterioscler Thromb Vasc Biol ;22:1175-80.

Lamarche B, Moorjani S, Lupien PJ, . (1996).

Apolipoprotein A-I and B levels and the risk of ischemic heart disease during a five-year follow-up of men in the Quebec Cardiovascular Study. Circulation ;94:273-278

Lloyd-Jones D, Adams RJ, Brown TM, et al. (2010).

Executive summary: heart disease and stroke statistics--2010 update: a report from the American Heart Association. Circulation; 121:948-54. 
Egyptian J. of Nutrition Vol. XXXV No. 2 (2020)

Liu MY, Xydakis AM, Hoogeveen RC, Jones PH, Smith EO, Nelson K, Ballantyne CM (2005).

Multiplexed analysis of biomarkers related to obesity and the metabolic syndrome in human plasma, using the Luminex-100 system. Clin Chem; 51:1102-9.

Lund-Katz S, Phillips MC (2010).

High density lipoprotein structure-function and role in reverse cholesterol transport. Subcell Biochem;51:183-227

Mahley RW, Innerarity TL, Rall Jr SC, Weisgraber KH (1984).

Plasma Lipoproteins: Apolipoprotein Structure and Function. J Lipid Re. Dec 1; 25(12):1277-94.

Mora S, Otvos JD, Rifai N, Rosenson RS, Buring JE, Ridker PM (2009).

Lipoprotein particle profiles by nuclear magnetic resonance compared with standard lipids and apolipoproteins in predicting incident cardiovascular disease in women. Circulation ;119:931-9.

Moreno JJ, Mitjavila MT (2003).

The degree of unsaturation of dietary fatty acids and the development of atherosclerosis (review). J Nutr Biochem; 14:182-95. 
Shymaa M. Ata.

Negre-Salvayre A, Dousset N, Ferretti G, Tixiana B, Curatola G, and Salvayre R (2006).

Antioxidant and cytoprotective properties of high-density lipoproteins in vascular cells. Free Radical biology and Medicine ; 41,7: 10310-1040.

Oram JF, Heinecke JW (2005).

ATP-binding cassette transporter A1: a cell cholesterol exporter that protects against cardiovascular disease. Physiol Rev ;85:1343-72.

Otvos JD (2002).

Measurement of lipoprotein subclass profiles by nuclear magnetic resonance spectroscopy. Clin Lab; 48:171-80.

Otvos J (1999).

Measurement of triglyceride-rich lipoproteins by nuclear magnetic resonance spectroscopy. Clin Cardiol;22:II21-7.

Ouimet M, Barrett TG, and Fisher EA (2019).

HDL and Reverse Cholesterol Transport Basic Mechanisms and Their Roles in Vascular Health and Disease. Circ Res. ;124:1505-1518.

Ross, R. (1999).

Atherosclerosis-An inflammatory disease. N. Engl. J. Med., 340, 115-126. 
Egyptian J. of Nutrition Vol. XXXV No. 2 (2020)

Sawrey-Kunicek L, Zhu C, Bardagiy AS, Rhodes CH, Sacchi R, Randolph JM, Steinberg FM, and Zickovic AM (2019).

Whole egg consumption compared with yolk-free egg increase the cholesterol efflux of high -density lipoproteins in overweight, postmenopausal women. Am J Clin Nutr; 110:617-627.

Sniderman A, Vu H, Cianflone K (1991).

Effect of moderate hypertriglyceridemia on the relation of plasma total and LDL apo B levels. Atherosclerosis; 89:10916.

St-Pierre AC, Cantin B, Dagenais GR, Despr'es J-P, Lamarche B (2006).

Apolipoprotein-B, low-density lipoprotein cholesterol, and the long-term risk of coronary heart disease in men. Am J Cardiol. ;97:997-1001.

Walldius G \& Jungner I (2004).

Apolipoprotein B and apolipoprotein A-I: risk indicators of coronary heart disease and targets for lipid-modifying therapy. Journal of Internal Medicine ; 255: 188-205

Walldius G, Jungner I, Holme I, Aastveit AH, Kolar W, Steiner E (2001).

High apolipoprotein B, low apolipoprotein A-I, and improvement in the prediction of fatal myocardial infarction (AMORIS study): a prospective study. Lancet ;358:20262033. 
Shymaa M. Ata.

Warnick GR, Benderson J, Albers JJ (1982).

Dextran sulfate-Mg2+ precipitation procedure for quantitation of high-density-lipoprotein cholesterol. Clin Chem ;28:137988.

Watkins LO (2004).

Epidemiology and Burden of Cardiovascular Disease. Clin. Cardiol. ; Vol. 27 (Suppl. III), III-2-III-6.

Wenzel AJ, Gerweck C, Barbato D, Nicolosi RJ, Handelman GJ, Curran-Celentano J (2006).

A 12-wk egg intervention increases serum zeaxanthin and macular pigment optical density in women. $J$ Nutr; 136:256873.

Williams K, Sniderman AD, Sattar N, D'Agostino $\mathbf{R} \mathrm{Jr}$, Wagenknecht LE, Haffner SM (2003).

Comparison of the associations of apolipoprotein B and lowdensity lipoprotein cholesterol with other cardiovascular risk factors in the Insulin Resistance Atherosclerosis Study (IRAS). Circulation. ; 108:2312-2316. 
Egyptian J. of Nutrition Vol. XXXV No. 2 (2020)

\title{
التلخل الغذائي المبني علي البيض لمدة r أسبوع يعزز مستويات الدهون وجزيئات البروتينات الاهنية في كبار السن
}

\author{
شيماء محسن عطا \\ مدرس التغذية و علوم الأطعمة ، قسم الإقتصاد المنزلي ، كلية التربية النوعية

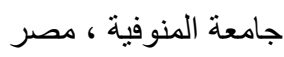

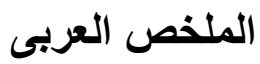

البيض مصدر جيد وغير مكلف للعناصر الغذائية المهمة مثل البروتين عالي الجودة ،

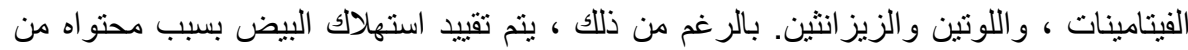

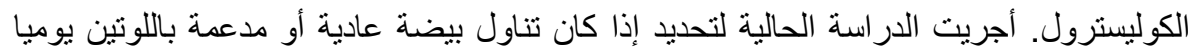

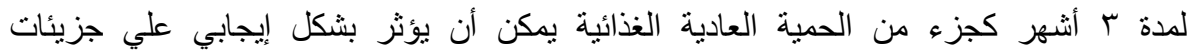

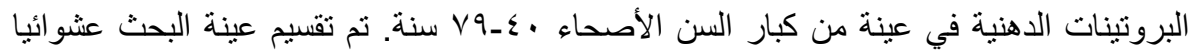

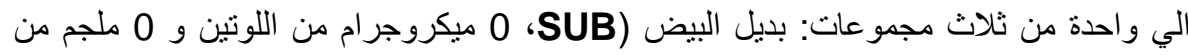

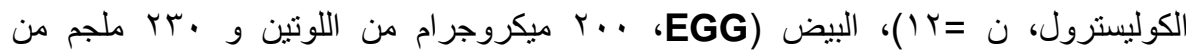

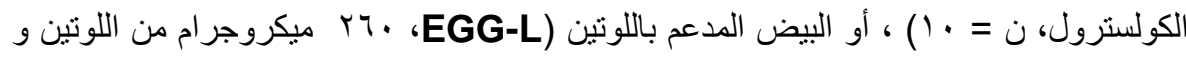

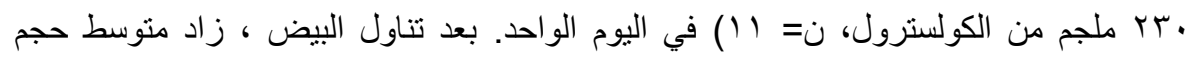

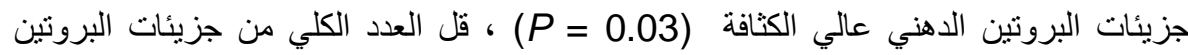

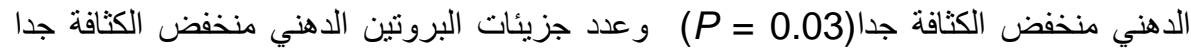

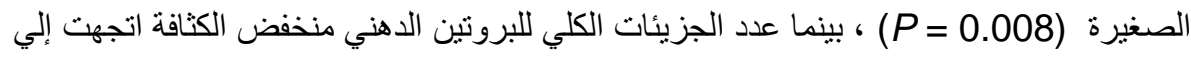

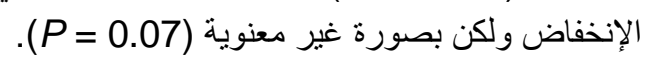

ارتبطت التغييرات في متوسط حجم جزيئات البروتين الدهني عالي الكثافة بصورة

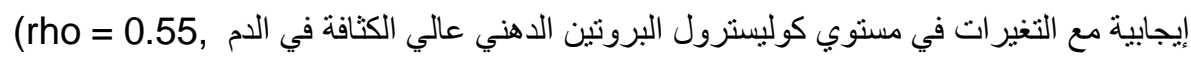

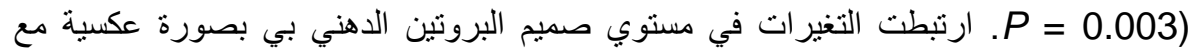

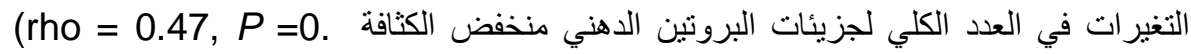

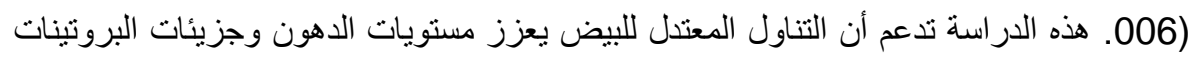

